\title{
Teleology and evolution education: introduction to the special issue
}

\author{
Marcus Hammann ${ }^{1 *}$ and Ross H. Nehm²
}

\section{Introduction}

Teleology is a major challenge to evolution educators who strive to provide students with a scientifically accurate understanding of evolution. Teleological explanations commonly appeal to ends, goal-directedness, agency, purpose, and intent. Teleological explanations of evolution include the ideas that organisms evolved according to some predetermined direction or plan, purposefully adjusted to new environments, or intentionally enacted evolutionary change; these are scientifically unacceptable teleological explanations.

There are two main reasons for addressing teleology in this special issue: First, evolution educators consider scientifically unacceptable teleological ideas to be major obstacles to students' understanding of evolution. Second, teleological explanations take multiple forms and there are scientifically acceptable and scientifically unacceptable types of teleology; fine distinctions are necessary in order to differentiate among them. Such distinctions, however, are rarely taught to students unless they take specialized courses in the philosophy of biology at the university level. There is consensus among most contributors to this special issue that teleological explanations should not be avoided altogether; rather, teachers and their students should be cognizant about the different types of teleology in order to develop robust evolutionary understanding.

*Correspondence: hammann.m@uni-muenster.de

${ }^{1}$ Centre for Biology Education, University of Münster, Schlossplatz 34, 48143 Münster, Germany

Full list of author information is available at the end of the article

\section{Contributions to the special issue}

In the biological sciences, teleological ideas and language are ubiquitous. The first article by Werth and Allchin (2020) provides numerous examples of teleology at different levels of biological organization (i.e., molecules, tissues, organs, organisms, populations and ecosystems) to substantiate the claim that teleological thinking is deeply entrenched in biology and is not limited to student thinking. In particular, Werth and Allchin argue that teleological thinking is an integral part of how people (including biologists) think and talk about nature. Common to teleological imagery, conceptualizations, and language is the idea that the biological world unfolds as a part of a prescribed plan. More generally, Werth and Allchin argue that teleology is intricately bound to normative ideas about how nature should be. According to the 'balance of nature' metaphor, for example, nature is believed to purposefully stay in balance. Furthermore, Werth and Allchin hypothesize that teleological reasoning may have evolutionary roots. Humans evolved in a social context and attributing agency to any observed behavior in the social environment may have been advantageous. Werth and Allchin's main argument, however, is that teleology blurs the distinction between normative and descriptive reasoning about nature: "Through teleology, nature becomes normative." Teleology's dark shadow, then, is the naturalizing error. More specifically, Werth and Allchin argue that the belief that nature embodies purpose can be easily used by humans to argue that human behavior, culture, and society should be modelled after nature. Teleology, thus, has cultural implications and the authors argue that educators need to address teleology in a range of biological and socio-cultural contexts.

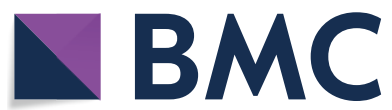

(c) The Author(s) 2020. This article is licensed under a Creative Commons Attribution 4.0 International License, which permits use, sharing, adaptation, distribution and reproduction in any medium or format, as long as you give appropriate credit to the original author(s) and the source, provide a link to the Creative Commons licence, and indicate if changes were made. The images or other third party material in this article are included in the article's Creative Commons licence, unless indicated otherwise in a credit line to the material. If material is not included in the article's Creative Commons licence and your intended use is not permitted by statutory regulation or exceeds the permitted use, you will need to obtain permission directly from the copyright holder. To view a copy of this licence, visit http://creativecommons.org/licenses/by/4.0/. The Creative Commons Public Domain Dedication waiver (http://creativecommons.org/publicdomain/zero/1.0/) applies to the data made available in this article, unless otherwise stated in a credit line to the data. 
Are students' teleological explanations problematic? Kampourakis (2020) answers this question by arguing that it is the underlying design stance and not teleology per se that renders teleological explanations problematic. Generally, teleological explanations make reference to a final end (telos). Looking at the nature of teleological explanations in detail, Kampourakis distinguishes between two types of teleology: explanations that are based on design (design teleology) and explanations that are based on natural selection (selection teleology). In design teleology, a feature exists because of an external agents' intention (external design teleology) or because of the intentions or needs of an organism (internal design teleology). External and internal design teleologies are clearly illegitimate in biology because there is evidence that organisms are not designed and because evolution does not follow intentions or needs. In selection teleology, an organism's features exist because of their consequences that contribute to survival and reproduction and are thus favored by natural selection. The contribution that the heart makes to the body, for example, is to pump blood. Therefore, Kampourakis argues, it is possible to reason that a feature performing a function exists because of the benefit that this function confers to the organism and because, as a result of this, it has been favored by natural selection. For this reason, it is not necessarily wrong if students express the idea that a feature exists in order to perform a function. The core challenge in evolution education is not students' teleological explanations, but the illegitimate assumption of external or internal design in such explanations.

Students tend to argue that the function of a trait is the only causal factor explaining why the trait came into existence without linking the function of the trait to evolutionary mechanisms. Trommler and Hammann (2020) explore the relationship between biological function and teleology. Drawing on a range of recent positions from the philosophy of biology, Trommler and Hammann argue that biologists use the notion of telos as an epistemological tool when they consider a structure or a mechanism to be functional. For example, biologists use survival and reproduction as epistemological reference points when attributing functions to structures (epistemological teleology) without making the assumption, of course, that survival and reproduction are ends inherent in nature. Ontological teleology, in contrast, is the inadequate assumption that functional structures and mechanisms came into existence because of their functionality. Means-ends analysesas an integral part of epistemological teleology-can be misleading to students, the authors argue, because students might confuse the idea that traits function and exist for survival (adequate epistemological teleological reasoning) with the idea that traits came into existence for the purpose of functioning and maintaining survival (inadequate ontological teleological reasoning). Such ontological reasoning is illegitimate because there are no 'ends' in nature. To teach students that nature is not directed towards ends, Trommler and Hammann suggest that students distinguish between biological functions and mechanisms, and educators explicitly address the fact that there are no ends in nature.

Given that attempts to completely eliminate teleological thinking from evolution education are philosophically problematic and educationally counterproductive, how should biology educators approach the topic of teleology? González Galli, Peréz, and Gómez Galindo's (2020) work seeks to answer this question. They review theoretical frameworks from science education and cognitive psychology and conclude that the most productive strategy would be to help students regulate their teleological thinking. Specifically, they emphasize that self-regulation requires both metacognitive knowledge (what we know about our thinking) and metacognitive regulation (how we control our thinking and learning). In line with prior research on metacognition, González Galli et al. advance a "metacognitive vigilance" perspective on teleology that involves three competencies: (i) knowledge of what teleology is, (ii) recognition of its multiple expressions and acceptable applications, and (iii) intentional regulation of its use. Student mastery of all three of these features emerges as an important learning outcome for evolution education. González Galli et al.s intriguing proposal bridges the divide between theoretical and practical discussions about teleology and motivates the development and application of educational materials that foster students' metacognitive vigilance.

Over the past several decades, "tree thinking" has emerged as an essential tool for biological reasoning and problem solving. An important but unanswered question in evolution education is whether the ways in which phylogenetics is taught influence students' teleological perspectives about the history of life on Earth. Schramm and Schmiemann (2019) engage with this important topic and identify multiple ways in which phylogenetics instruction can inadvertently reinforce teleological thinking (e.g., presenting taxa in order of biological complexity aligns with pop-culture iconographies of 'the great chain of being'; positioning focal taxa such as humans on the outermost edges of phylogenies reinforces notions of evolutionary goals and "development"). After identifying teleological pitfalls, Schramm and Schmiemann provide practical teaching strategies for overcoming them (e.g., altering focal taxa placement, rotating topologies, using 'evograms'). Their paper also 
identifies important gaps in the literature on teleology and motivates future empirical studies on the role that phylogenetics instruction could play in altering students' teleological thinking across biological scales (e.g., micro-, macroevolution).

The final two articles focus on young learners. Gresch (2020) presents a video-based analysis of a seventhgrade biology course on evolution. In the teaching unit, the students engage in the activity of designing an imaginary animal perfectly adapted to its environment. Later in the unit, the teacher addresses the evolution of whales and the students are encouraged to discuss the statement "evolution has no goal". Gresch's analyses focus on how the teacher and the students situationally address teleology. Additional interviews provide insights into how the teacher's teaching norms and rationale relate to teaching practices regarding teleology. Using a documentary method for analyzing the videos of the lessons, Gresch (2020) argues that the teacher encourages the students to elaborate on their teleological explanations and eventually validates them. Thus, Gresch characterizes the teacher's practices in the unit on evolution as ambiguous: Although the teacher aims at the biologically correct view of evolution, he does not clearly reject students' teleological ideas about internal needs and goal-directed evolution because, among other reasons, he does not want to demotivate them. Teaching norms are clearly in conflict because the teacher values both student creativity - which often involves teleological reasoning-and scientifically correct ideas. The result is a confusing combination of teleological and scientific elements in the teaching unit on evolution, and the teacher offers no clear evidence that evolution has no goals. Gresch suggests that videos or transcripts of classroom interactions are a rich but underutilized resource for preservice teacher professional development.

It is widely recognized that teleological thinking emerges very early in human development, and for most biological phenomena young children prefer teleological explanations over mechanistic ones. However, few studies have empirically examined whether teleological thinking is a barrier to learning about natural selection in young children. Brown, Ronfard, and Kelemen (2020) advance work in this area in multiple ways. First, they investigate the impact of a teacher-led (but researcherdesigned) storybook intervention on young children's teleological thinking in a school setting; prior studies, in contrast, have largely been researcher-led, smallscale, and lab-based. Second, they generate a conceptual framework for characterizing teleological ideas (e.g., explicit teleology, ambiguous, elaborated) that permits careful scrutiny of whether more or less elaborated teleological ideas differentially impact learning. Third, they examine whether teleological ideas pose a greater challenge to learning natural selection compared to other preconceptions. Brown et al. report on impressive learning gains in response to the teacher-led intervention and demonstrate that teleology is much less of a barrier to learning than expected. Their work calls into question the notion that young children are only capable of learning isolated facts about evolution and motivates further studies of more mechanistically-based evolutionary concepts. The findings also raise fundamental questions about why teleological ideas appear to present much less of a barrier to learning natural selection in young children than in young adults.

\section{Next steps for evolution education}

The collection of articles in this special issue advance theory relating to the role that teleological ideas should play in evolution education and practice concerning how educators should engage with student ideas about teleology.

One strand of argumentation in this special issue emphasizes that teleological ideas are an obstacle to students' understanding of evolution. More specifically, novice learners often struggle with understanding evolutionary concepts because they prefer the intuitive teleological ideas of goal-driven and intentional change to scientifically acceptable-but more complexexplanations grounded in evolutionary processes. In particular, many students think that organisms need to adapt to new environments in order to survive. Therefore, biology educators consider "the need to adapt" and "the need to survive" as major teleological misconceptions. Taking such unacceptable teleological explanations into consideration, several authors in this special issue discuss ways in which evolution can-and shouldbe taught so that students understand that evolution is characterized by the absence of ends and purposes. Furthermore, evolution is neither predetermined nor guided by intention. In particular, the argument is made that teleological reasoning must be addressed (rather than eliminated) because it causes substantial difficulties in understanding evolutionary mechanisms. This also includes educational reflections on how to avoid typical teleological pitfalls when teachers use external representations, like phylogenetic trees.

A second strand of argumentation regarding the role that teleological ideas should play in evolution education is that teleology is an ambiguous concept because there are scientifically acceptable types and scientifically unacceptable types of teleology. Several contributions in this special issue draw on positions in the philosophy of biology to elaborate on the fact that teleological reasoning takes many forms. Not all of the multiple forms of 
teleology are scientifically and educationally problematic. Important acceptable types of teleology focus on the notion of biological function, which is a teleological idea because biological structures are conceptualized as a means to an end. As a consequence, several authors in this special issue argue that students would benefit from instruction about acceptable and unacceptable forms of teleology at a meta-level. Instead of avoiding teleology altogether, which is questionable given that biologists use teleological reasoning themselves, students need to distinguish between acceptable and unacceptable forms of teleology and regulate their use.

Concerning practice, the authors in the special issue largely agree that (1) only some forms of teleology are scientifically and educationally problematic and (2) explicit attention to teleology is needed in biology classrooms. Teleology, therefore, cannot and should not be eliminated from the teaching of biology and evolution. Rather, teleology needs to be addressed in ways that enable students to avoid the pitfalls of scientifically and educationally problematic forms of teleological reasoning. In particular, Werth and Allchin (2020) suggest coupling teleological and non-teleological perspectives together so that students understand the differences between explanations characterized by teleological (and normative) purpose and the nonteleological descriptive alternative. Kampourakis (2020) suggests explicitly addressing design teleology and creating conceptual conflict so that students understand that design-based explanations are problematic. $\mathrm{He}$ also suggests comparing and contrasting acceptable natural selection teleology and unacceptable design teleology. Trommler and Hammann (2020) propose explicitly addressing acceptable epistemological teleology and unacceptable ontological teleology to prevent students from unknowingly slipping from one form of teleology into another. González Galli et al. (2020) suggest familiarizing students with the different forms of acceptable and unacceptable teleology in a range of different contexts so that students can distinguish between them and metacognitively regulate their use. Collectively, this work motivates a reformulation of how educators approach teleology in evolution education.

Future perspectives for evolution education and research also emerge from the three contributions in this special issue devoted to reading evolutionary trees, videobased analyses of classroom practices, and the teaching of evolution to young children. Focusing on the teleological pitfalls of reading evolutionary trees, Schramm and Schmiemann (2019) hypothesize that teleological mindsets, tree design, and fragmentary knowledge about evolution interact and argue that experimental research approaches are needed to investigate these interactions.
This is a valuable research perspective for the interface between teleology and representational competence. Gresch (2020) identifies ambiguous teaching practices in his video-based analyses of an evolution unit and suggests using classroom videos to prepare future biology teachers. Such approaches could help future biology teachers avoid confusing ambiguities regarding teleology in their classrooms. Gresch argues for evaluating the effectiveness of such novel approaches to teacher professional development. Brown, Ronfard and Kelemen (2020) provide evidence from a teaching intervention showing that young children are surprisingly good at overcoming teleological reasoning in evolution. They suggest future research on conceptual restructuring in young children to build upon their encouraging results.

Overall, this special issue on evolution education and teleology marks an important turning point; scholars from many disciplines (education, philosophy, psychology) are moving away from an "eliminative" perspective on teleology and towards a more nuanced stance that differentiates acceptable and unacceptable forms of it. In order for this more informed perspective to be adopted in evolution education, nearly all of the authors of the special issue argue for explicit attention to teleology in the classroom. Educational design and development work is needed to make this possible. For example: resources about forms of teleological reasoning and language should be included in teacher education programs; age-appropriate curriculum materials are needed to help students understand what teleology is and how to differentiate acceptable and unacceptable forms of it; metacognitive strategies must be operationalized for use in classrooms; and assessments for measuring student thinking about evolution must be revised to encompass updated perspectives on teleology. As this special issue makes clear, important conceptual progress is being made concerning teleology and evolution education, and future work must be directed at more practical educational applications. The contributions of the special issue have provided an important first step for addressing one of evolution education's greatest challenges.

\section{Acknowledgements}

We thank the authors for their contributions to the special issue.

\section{Authors' contributions}

Both authors contributed to the writing of the editorial in alignment with order of authorship. Both authors read and approved the final manuscript.

\section{Funding}

Funding for this study was provided by the Howard Hughes Medical Institute Inclusive Excellence Science Education fund.

Availability of data and materials Not applicable. 
Ethics approval and consent to participate

Not applicable.

\section{Consent for publication}

Not applicable.

\section{Competing interests}

The authors declare that they have no competing interests.

\section{Author details}

${ }^{1}$ Centre for Biology Education, University of Münster, Schlossplatz 34, 48143 Münster, Germany. ${ }^{2}$ Department of Ecology and Evolution, Program in Science Education, Stony Brook University, Stony Brook, NY 11794, USA.

Received: 1 July 2020 Accepted: 2 July 2020

Published online: 07 July 2020

\section{References}

Brown SA, Ronfard S, Kelemen D. Teaching natural selection in early elementary classrooms: can a storybook intervention reduce teleological misunderstandings? Evol Educ Outreach. 2020;13:12. https://doi.org/10.1186/ s12052-020-00127-7.
González Galli L, Peréz G, Gómez Galindo AA. The self-regulation of teleological thinking in natural selection learning. Evol Educ Outreach. 2020;13:6. https://doi.org/10.1186/s12052-020-00120-0.

Gresch H. Teleological explanations in evolution classes: video-based analyses of teaching and learning processes across a seventh-grade teaching unit. Evol Educ Outreach. 2020;13:10. https://doi.org/10.1186/s1205 2-020-00125-9.

Kampourakis K. Students'"teleological misconceptions" in evolution education: why the underlying design stance, not teleology per se, is the problem. Evol Educ Outreach. 2020;13:1. https://doi.org/10.1186/s1205 2-019-0116-z

Schramm T, Schmiemann P. Teleological pitfalls in reading evolutionary trees and ways to avoid them. Evol Educ Outreach. 2019;12:20. https://doi. org/10.1186/s12052-019-0112-3.

Trommler F, Hammann M. The relationship between biological function and teleology: implications for biology education. Evol Educ Outreach. 2020;13:11. https://doi.org/10.1186/s12052-020-00122-y.

Werth A, Allchin D. Teleology's long shadow. Evol Educ Outreach. 2020;13:4. https://doi.org/10.1186/s12052-020-00118-8.

\section{Publisher's Note}

Springer Nature remains neutral with regard to jurisdictional claims in published maps and institutional affiliations.
Ready to submit your research? Choose BMC and benefit from:

- fast, convenient online submission

- thorough peer review by experienced researchers in your field

- rapid publication on acceptance

- support for research data, including large and complex data types

- gold Open Access which fosters wider collaboration and increased citations

- maximum visibility for your research: over $100 \mathrm{M}$ website views per year

At BMC, research is always in progress.

Learn more biomedcentral.com/submissions 